\title{
Bacillus subtilis RarA forms damage-inducible foci that scan the entire cell
}

\author{
Rogelio Hernández-Tamayo $0^{1,2}$ and Peter L. Graumann ${ }^{1,2^{*}}$ (D)
}

\begin{abstract}
Objectives: Little is known about the activity and dynamics of ATPase RarA in B. subtilis, proposed to act at stalled DNA replication forks due to DNA damage. We performed fluorescence microscopy time lapse experiments with a functional RarA-mVenus fusion to visualize the dynamics of RarA during conditions that generate DNA damage.

Data description: In exponentially growing cells, we observed that $15 \%$ of the cells contained single RarA-mV (mVenus fluorescent fusion) foci moving throughout the entire cell between 3 min intervals. This percentage remained constant at different time points, indicating that focus formation during unperturbed growth is maintained at about a constant rate. When cells were exposed to stress conditions, the population of cells containing RarA-mV foci tripled after 60 min. Cells exposed to two DNA-damaging drugs, to $5 \mathrm{mM} \mathrm{MMS}$ or to $0.5 \mathrm{mM} \mathrm{H}_{2} \mathrm{O}_{2}$, showed a similar type of response, with RarA-mVenus foci moving more slowly than during unperturbed growth. It is likely that RarA-mV contributes to the repair of $\mathrm{H}_{2} \mathrm{O}_{2}$-induced lesions, and to a minor extent to MMS-induced lesions. The presence of foci in growing cells suggests that RarA also plays a role during the cell cycle, at least in a fraction of cells, possibly contributing to heterogeneity of response to DNA damage.
\end{abstract}

Keywords: RarA, DNA repair, Time lapse fluorescence microscopy, Bacillus subtilis, Stress response

\section{Objective}

The bacterial replication-associated recombination protein A, RarA, belongs to a highly conserved family of ATPases, including the yeast Mgs1 and mammal WRNIP1 proteins [1]. The $B$. subtilis rarA gene, which is monocistronic, is constitutively expressed, but its expression is markedly enhanced by stressors such as diamide, ethanol, high salt or $\mathrm{H}_{2} \mathrm{O}_{2}$ [2]. RarA protein plays an important, but poorly understood role in genome maintenance [3]. Although several studies agreed with the idea that RarA acts in both replication and recombination processes, the concrete function is still unknown. $E$. coli RarA, which is co-expressed with FtsK, co-localizes/ interacts with SeqA, RecQ [4], UvrD [5] or RecA [6] and may act at blocked forks in certain replication mutants $[5,6]$. In vitro, E. coli RarA interacts with single strand binding (SSB) protein and shows helicase activity that

\footnotetext{
*Correspondence: graumanp@uni-marburg.de

${ }^{2}$ Department of Chemistry, Philipps Universität Marburg,

Hans-Meerwein-Straße 6, 35032 Marburg, Germany

Full list of author information is available at the end of the article
}

preferentially unwinds $3^{\prime}$-ends from dsDNA ends or ssDNA gaps, suggesting that RarA could act at stalled replication forks [1, 7]. One common point of RarA studies is the complex scenario required to produce a clear phenotype that explains all observations.

\section{Data description}

A C-terminal fusion of the fluorescent protein mVenus to RarA was generated by cloning the $3^{\prime}$-end $500 \mathrm{bp}$ of rarA (excluding the stop codon) into plasmid pSG1164 [8], which was integrated into the rarA gene locus on the B. subtilis chromosome by homologous recombination. We have used epifluorescence microscopy time-lapse to monitor foci formation and dynamics of RarA before and after stress conditions at $30^{\circ} \mathrm{C}\left(\mathrm{OD}_{600}=\sim 0.3\right)$. Cells were either treated with $0.5 \mathrm{mM} \mathrm{H}_{2} \mathrm{O}_{2}$, or with $5 \mathrm{mM}$ MMS (both obtained from Sigma Aldrich) or were not treated. For fluorescence microscopy, B. subtilis cells were grown in $\mathrm{S}_{50}$ minimal medium [9] at $30{ }^{\circ} \mathrm{C}$ under shaking conditions until exponential growth. Three microliters of cells were transferred on an agarose slide-a glass slide 
Table 1 Overview of data files/data sets

\begin{tabular}{llll}
\hline Label & Name of data file/data set & $\begin{array}{l}\text { File types (file } \\
\text { extension) }\end{array}$ & $\begin{array}{l}\text { Data repository and identifier (DOI } \\
\text { or accession number) }\end{array}$ \\
\hline Data file 1 [10] & RarA-mV WT & Time lapse AVI & https://doi.org/10.6084/m9.figshare.7461587.v3 \\
Data file 2 [11] & RarA-mV MMS & Time lapse AVI & https://doi.org/10.6084/m9.figshare.7461692.v2 \\
Data file 3 [12] & RarA-mV H $\mathrm{O}_{2}$ & Time lapse AVI & https://doi.org/10.6084/m9.figshare.7461698.v2 \\
Data set 1 [14] & Gaussian mixture model (GMM) RarA-mV & Image tif & https://doi.org/10.6084/m9.figshare.7466987.v3 \\
\hline
\end{tabular}

(microscope slides standard, Roth) coated with an agarose layer ( $\mathrm{S}_{50}$ minimal medium, $1 \% \mathrm{v} / \mathrm{v}$ agarose) and covered with a cover slip (Roth). Fluorescence microscopy was performed using a Zeiss Observer Z1 (Carl Zeiss) with an oil immersion objective $(100 \times$ magnification, NA 1.45 alpha Plan-FLUAR) and a CCD camera (CoolSNAP EZ, Photometrics), or with a BX51 microscope (Olympus) with a Cool Snap EZ camera (Photometrics) and a xenon light source (Olympus). Electronic data were processed using Metamorph 7.5.5.0 software (Molecular Devices, Sunnyvale, CA, USA), which also allows the calibration of the fluorescence intensity and pixel size to determine the cell length, time-lapse epifluorescence microscopy of RarA-mV were collected every $3 \mathrm{~min}$.

In epifluorescence, an accumulation of fluorescent molecules is needed for detection, so it is reasonable to say that in exponentially growing cells, and to a higher extent in response to drugs that produce DNA damage, $\operatorname{Rar} A$ is recruited to mobile assemblies within the cell. In case of induced DNA damage, RarA is assembled into foci in twice to three times as many cells than under exponential growth conditions (Table 1). The intensity of the response, considered as the increase of the percentage of cells containing RarA-mV foci, was $100 \%$ higher after MMS (from 15 to $30 \%, \mathrm{n}=125$ ), and $\mathrm{H}_{2} \mathrm{O}_{2}$ addition produced an increase in the population of cells containing foci to about $40 \%$ of all cells imaged $(n=120)$. Movies 1 to 3 [10-12] show that RarA-mVenus foci moved throughout the cells with no apparent spatial specificity (Table 1, data file 1-3). As under exponential growth conditions [13], RarA-mVenus foci in hydrogen peroxide-stressed cells moved continuously with stochastic halts, and moved through the entire space of the cell. In about $10 \%$ of the cells containing foci, these appeared at some time point of the experiment or disappeared; in the remaining cells, foci were continuously present. Visually, movement of RarA could not be distinguished between stressed and non-stressed cells, merely the number of cells containing foci increased in cells repairing induced damage. However, automated tracking of focus movement and Gaussian mixture model (GMM) analyses (Data set 1) [14] showed two Gaussian distributions, corresponding to a slower/static and a faster/mobile fraction of RarA-mV assemblies, with diffusion constants of $D_{\text {static }}=3.12 \mu \mathrm{m}^{2} \mathrm{~min}^{-1}$ or $D_{\text {mobile }}=31.8 \mu \mathrm{m}^{2} \mathrm{~min}^{-1}$, under different growth conditions. Analyses of dynamics of single particles and determination of static and mobile fractions were performed using the Matlab-based graphical user interphase program SMTracker [15]. Compared to unperturbed growth, movement of RarA-mV became considerably slower after addition of MMS or $\mathrm{H}_{2} \mathrm{O}_{2}$ : in contrast to $78 \%$ dynamic and $22 \%$ slow/static foci during exponential growth, MMS-treated cells showed 34\% dynamic and $66 \%$ static foci, and $\mathrm{H}_{2} \mathrm{O}_{2}$-treated cells $36 \%$ dynamic and $64 \%$ static foci. RarA molecules never arrested for many minutes but continued scanning the cell, and were much longer-lived than e.g. $\operatorname{RecN}$ foci [16].

\section{Limitations}

This study extends observation of RarA-mVenus foci during unperturbed growth [13]. The study reveals the movement of an assembly of RarA molecules in a subset of a cell population; it does not describe the dynamics of freely diffusing molecules. Although clearly, foci are only present in a minority of cells, even after stress induction, very small assemblies may be present in more cells, but may be undetectable through epifluorescence microscopy.

\section{Abbreviations}

Mgs1: maintenance of genome stability 1; WRNIP1: Werner [WRN] Interacting Protein 1; MMS: methyl methane sulfonate; $\mathrm{H}_{2} \mathrm{O}_{2}$ : peroxide water; GMM: Gaussian mixture model.

\section{Authors' contributions}

$\mathrm{RH}-\mathrm{T}$ and PLG conceived of the project and wrote the manuscript, $\mathrm{RH}-\mathrm{T}$ performed epifluorescence imaging and other experiments, and analyzed the data. Both authors read and approved the final manuscript.

\section{Author details \\ 1 SYNMIKRO, LOEWE Center for Synthetic Microbiology, Marburg, Germany. ${ }^{2}$ Department of Chemistry, Philipps Universität Marburg, Hans-Meer- wein-Straße 6, 35032 Marburg, Germany.}

\section{Acknowledgements}

LOEWE funding (state of Hessen, Germany) to SYNMIKRO for supporting this work.

Competing interests

The authors declare that they have no competing interests. 


\section{Availability of data materials}

The data described in this Data note can be freely and openly accessed on [https://figshare.com], namely https://doi.org/10.6084/m9.figsh are.7461587.v3, https://doi.org/10.6084/m9.figshare.7461692.v2, https:// doi.org/10.6084/m9.figshare.7461698.v2, https://doi.org/10.6084/m9.figsh are.7466987.v3.

\section{Consent for publication}

Not applicable.

\section{Ethics approval and consent to participate}

Not applicable.

\section{Funding}

This work was supported by LOEWE funding to SYNMIKRO (state of Hessen) and by the Philipps Universität Marburg. The funding bodies played no role in the design of the study and collection, analysis, and interpretation of data and in writing the manuscript. This study was funded by Deutsche Forschungsgemeinschaft (TRR174).

\section{Publisher's Note}

Springer Nature remains neutral with regard to jurisdictional claims in published maps and institutional affiliations.

Received: 19 December 2018 Accepted: 3 April 2019

Published online: 11 April 2019

\section{References}

1. Stanage TH, Page AN, Cox MM. DNA flap creation by the RarA/MgsA protein of Escherichia coli. Nucleic Acids Res. 2017;45(5):2724-35.

2. Lundin C, North M, Erixon K, Walters K, Jenssen D, Goldman ASH, et al. Methyl methanesulfonate (MMS) produces heat-labile DNA damage but no detectable in vivo DNA double-strand breaks. Nucleic Acids Res. 2005;33:3799 [Erratum in: Nucleic Acids Res. 2012;40(12):5794].

3. Carrasco B, Seco EM, Lopez-Sanz M, Alonso JC, Ayora S. BacilIus subtilis RarA modulates replication restart. Nucleic Acids Res. 2018;46(14):7206-20.
4. Sherratt DJ, Soballe B, Barre FX, Filipe S, Lau I, Massey T, et al. Recombination and chromosome segregation. Philos Trans R Soc B. 2004;359(1441):61-9.

5. Lestini R, Michel B. UvrD controls the access of recombination proteins to blocked replication forks. EMBO J. 2007;26(16):3804-14.

6. Shibata T, Hishida T, Kubota Y, Han YW, Iwasaki H, Shinagawa H. Functional overlap between RecA and MgsA (RarA) in the rescue of stalled replication forks in Escherichia coli. Genes Cells. 2005;10(3):181-91.

7. Page AN, George NP, Marceau AH, Cox MM, Keck JL. Structure and biochemical activities of Escherichia coli MgsA. J Biol Chem. 2011;286:14.

8. Feucht A, Lewis PJ. Improved plasmid vectors for the production of multiple fluorescent protein fusions in Bacillus subtilis. Gene. 2001;264(2):289-97.

9. Jaacks KJ, Healy J, Losick R, Grossman AD. Identification and characterization of genes controlled by the sporulation regulatory gene $\mathrm{spoOH}$ in Bacillus subtilis. J Bacteriol. 1989;171:4121-9.

10. Hernandez-Tamayo R, Graumann PL. RarA-mVWT. figshare. Media. 2018. https://doi.org/10.6084/m9.figshare.7461587.v3.

11. Hernandez-Tamayo R, Graumann PL. RarA-mV MMS. figshare. Media. 2018. https://doi.org/10.6084/m9.figshare.7461692.v2.

12. Hernandez-Tamayo R, Graumann PL. RarA-mV H202. figshare. Media. 2018. https://doi.org/10.6084/m9.figshare.7461698.v2.

13. Romero H, Rosch TC, Hernandez-Tamayo R, Lucena D, Ayora S, Alonso JC, et al. Single molecule tracking reveals functions for RarA at replication forks but also independently from replication during DNA repair in Bacillus subtilis. Sci Rep. 2019;9(1):1997.

14. Hernandez-Tamayo R, Graumann PL. Gaussian mixture model (GMM) RarA-mV. figshare. Figure. 2018. https://doi.org/10.6084/m9.figsh are.7466987.v3.

15. Rosch TC, Oviedo-Bocanegra LM, Fritz G, Graumann PL. SMTracker: a tool for quantitative analysis, exploration and visualization of single-molecule tracking data reveals highly dynamic binding of $B$. subtilis global repressor AbrB throughout the genome. Sci Rep. 2018;8(1):15747.

16. Rosch TC, Altenburger S, Oviedo-Bocanegra L, Pediaditakis M, El Najjar N, Fritz $\mathrm{G}$, et al. Single molecule tracking reveals spatio-temporal dynamics of bacterial DNA repair centres. Sci Rep. 2018;8:16450.
Ready to submit your research? Choose BMC and benefit from:

- fast, convenient online submission

- thorough peer review by experienced researchers in your field

- rapid publication on acceptance

- support for research data, including large and complex data types

- gold Open Access which fosters wider collaboration and increased citations

- maximum visibility for your research: over $100 \mathrm{M}$ website views per year

At BMC, research is always in progress.

Learn more biomedcentral.com/submissions 